\title{
Acceptability of option B+ among HIV positive women receiving antenatal and postnatal care services in selected health centre's in Lusaka
}

Bridget Chomba Chanda ${ }^{1,2^{*}}$, Rosemary Ndonyo Likwa ${ }^{2}$, Jessy Zgambo ${ }^{3}$, Louis Tembo ${ }^{4}$ and Choolwe Jacobs ${ }^{3}$

\begin{abstract}
Background: In 2013, Zambia accepted the immediate operationalization of Option B+, a policy used to try and eliminate mother to child transmission. This policy requires all HIV-positive pregnant and breastfeeding women to initiate antiretroviral treatment for life regardless of CD4 count. However, not all HIV positive women accept treatment for life. This study aimed to investigate acceptability of lifelong ART (Option B+) among HIV positive women receiving antenatal and postnatal services at the university teaching hospital and Lusaka urban city clinics.

Methods: This was a cross sectional study conducted in November, 2016 to March 2017. The study population comprised of HIV positive women in their reproductive age (15-49 years). A Structured questionnaire was used to collect data in a face to face interview with the participants. Data was entered in EpiData version 3.1 and analysed using Stata version 13. Multivariate logistic regression analysis was performed to determine predictors of acceptability.

Results: Overall, 427 women participated in this study. Their mean age was 30 years. Of the 427, over half (54\%) had inadequate knowledge and about $30 \%$ of the women in the study still experience stigma and discrimination. $63.2 \%$ of the women had good attitude towards Option B+ and overall, the majority (77.8\%) were willing to accept antiretroviral therapy for life. Multivariate analysis showed that only women with good attitude were 9.4 times more likely to accept Option B+ than those with a bad attitude [OR: 9.4: 95\%Cl, 5.8-15.2)].

Conclusion: This study showed that in general, women accepted initiation of Option B+. However, there is still a gap in the level of knowledge of Option B+ as well as stigma and discrimination in some communities, hence there is need to intensify programs that are aimed at educating the community on the importance of ART for life, combat stigma and discrimination and consequently promote acceptability of Option B+.
\end{abstract}

Keywords: Acceptability, Antiretroviral therapy, Option B +, Prevention of mother to child transmission; knowledge, Attitude, Discrimination

\footnotetext{
* Correspondence: chandabridget@gmail.com

'Department of Paediatric and Child Health, University Teaching

Hospital-HIV/AIDS Program, P.O Box, 50440 Lusaka, Zambia

${ }^{2}$ Department of population studies and Nutrition, School of Public Health,

University of Zambia, Geneva, Switzerland

Full list of author information is available at the end of the article
}

(c) The Author(s). 2018 Open Access This article is distributed under the terms of the Creative Commons Attribution 4.0 International License (http://creativecommons.org/licenses/by/4.0/), which permits unrestricted use, distribution, and reproduction in any medium, provided you give appropriate credit to the original author(s) and the source, provide a link to the Creative Commons license, and indicate if changes were made. The Creative Commons Public Domain Dedication waiver (http://creativecommons.org/publicdomain/zero/1.0/) applies to the data made available in this article, unless otherwise stated. 


\section{Background}

About 160,000 new HIV infections among children aged 0-14 occurred in 2016, dramatically declining from 300,000 in 2010. Progress in reducing mother-to-child transmission of HIV has been dramatic since the introduction in 2011 of the 'Global Plan towards the Elimination of New HIV Infections among Children, and Keeping their Mothers Alive', largely because of increased access to PMTCT-related services and increased number of pregnant women living with HIV being initiated on lifelong antiretroviral medicines [1]. But it has not been fast enough to reach the 2020 targets set by UNAIDS and partners as part of the Super-Fast-Track Framework to end AIDS. Acceleration of treatment for all pregnant and breastfeeding women living with HIV is still needed to achieve elimination of new infections among children and halve HIV-related deaths among pregnant women and new mothers [1].

Under WHO's 2010 PMTCT ARV guidance, countries had the option to choose between two prophylaxis regimens for pregnant women living with HIV with CD4 greater than 350cells/mm3. Option A and Option B. Under Option A, women received antenatal and intrapartum antiretroviral prophylaxis along with an antiretroviral postpartum "tail" regimen to reduce risk of drug resistance, while infants receive postpartum antiretroviral prophylaxis throughout the duration of breastfeeding [2].

Option B, on the other hand, has a simpler clinical flow in which all pregnant and lactating women with HIV initially are offered ART - beginning in the antenatal period and continuing throughout the duration of breastfeeding. At the end of breastfeeding those women who do not yet require ART for their own health would discontinue the prophylaxis and continue to monitor their CD4 count, eventually re-starting ART when the CD4 falls below 350cells/mm3. Along with these two options a third approach is now being used, Option $\mathrm{B}+$, in which all pregnant women living with HIV are offered life-long ART, regardless of their CD4 count [2].

To achieve the goal of elimination of mother to child transmission (eMTCT), in 2013, the Zambian government accepted the immediate operationalization of Option $\mathrm{B}+[3]$. This is done with the understanding that all HIV positive women are to be initiated on antiretroviral therapy (ART) for life. Antiretroviral therapy offers women the best chance of preventing mother to child transmission, however, not all HIV positive women are willing to accept ART for life.

Katirayi et al. [4] found that women reported difficulty around learning their HIV status and initiating ART on the same day. They needed time to think about ART initiation and wanted to first discuss with their partners before committing to lifelong treatment. A study conducted in Zimbabwe found that pregnant and lactating women find it easy to accept lifelong therapy because it is similar to taking medication for diabetes or birth control [5].

Other studies have identified attitudes towards lifelong treatment [6], knowledge of prevention of mother to child transmission [7], social demographic [8] and cultural characteristics [9] as factors that determine acceptability of Option B+. However, the impact of these factors may vary depending on the study setting and study population.

Overall, the evidence regarding how women's experiences in PMTCT option $\mathrm{B}+$ services affect their subsequent care-seeking behaviour remains sparse. This appears particularly true with regard to the uptake of both long-term HIV care and treatment for the woman's own HIV infection and infant HIV testing and related services. However, women's experiences of and perspectives on current and proposed interventions and how these influence subsequent care-seeking behaviour need to be better understood to ensure that an appropriate and acceptable package of services could be offered and that the virtual elimination of mother-to-child HIV transmission become an attainable goal [10].

A study on acceptability of Option B+ among HIV positive pregnant and breastfeeding women is of supreme value in understanding the factors that inhibit enrolment on lifelong ART. During the implementation of different regimens for PMTCT, the efficacy of a regimen is not the only important aspect to consider but the way in which the people accept it will determine how well or how poorly it will work.

Study findings on the acceptability of Option B+ among Zambian women are limited. This study was conducted to determine acceptability of Option B+ and associated factors among HIV positive women receiving antenatal and postnatal care services at UTH and Lusaka Urban City Clinics. The information generated may be used to aid policy makers and HIV care givers in improving programmes aimed at encouraging the uptake of ART for life among pregnant and breastfeeding women and improve maternal health.

\section{Methods}

\section{Study design and study setting}

This was a cross sectional study conducted in five health centers in Lusaka from November, 2016 to March 2017. In Lusaka district, Maternal Child Health $(\mathrm{MCH})$ and PMTCT services are offered in 24 of the 28 health centers and in all the health posts. The study sites (UTH, Matero Ref, Chawama, Kalingalinga and Chilenje) were chosen because they are in high density areas, offer antenatal, postnatal and PMTCT services. 


\section{Sample size determination}

A single population proportion formula was used to determine the study sample size with 95\% confidence interval, $50 \%$ proportion, a precision of 5 and $10 \%$ non-response rate. The overall estimated sample size was 427 . The study population comprised of HIV positive women who were attending antenatal and postnatal care services at the selected health centres and the target age group were women in the reproductive age (15-49). Exclusion criteria were HIV positive women with inability to communicate, HIV positive women who did not consent to take part in the study and all HIV negative women.

\section{Sampling method}

This study used Stratified Random Sampling. Drawing from a total of 12 government owned delivery health facilities that reported their 2015 PMTCT annual program results to PEPFAR Zambia, five health facilities were selected. The chosen clinics and hospital were treated as strata's. The number of women to be included in each health facility was worked out in proportion to the population of HIV positive women in each facility. Simple random sampling (SRS) was then used to select the study participants. The target population was selected from each health facility using a sampling list (PMTCT Register), taking into account the inclusion and exclusion criteria. The women were identified by their hospital numbers. These numbers were written on separate pieces of paper, folded and mixed into a box to conduct a lottery.

\section{Data collection and analysis}

A structured interviewer administered questionnaire was used to collect data. Prior to administration of the questionnaire, a pilot study was conducted to check for appropriateness and consistency. The questionnaire was translated into Nyanja for those that did not understand or speak English. The questionnaire was divided into four sections namely, a) Socio-demographic factors, b) Knowledge of Option B+, c) Attitudes towards Option B + and D) Socio-cultural factors.

Data was entered into EpiData version 3.1 and analyzed using Stata IC 13-64-bit (STATA Corporation, College Station, TX, USA) for analysis. Frequencies and proportions were used to describe the study participants. The statistical significance in this study was set at 5\% $(0.05)$ and confidence interval at $95 \%$. Acceptability was the main outcome variable in this study and was binary. Independent variables associated with acceptability of Option $\mathrm{B}+$ were analysed using logistic regression analysis. Univariate and multivariate logistic regression analysis were employed. The level of knowledge was measured from a score of five questions from the questionnaire, a score of four and five was graded as adequate knowledge and any score from 0 to 3 was graded as inadequate knowledge $[6,10]$. Attitude was also measured using scores. A score of 3 was graded as good attitude and any score of 2 questions or less was graded as bad attitude [6, 10]. All variables found to be significantly associated with acceptability were included for multivariate logistic regression analysis to control for confounders.

\section{Ethics and consent}

Ethical approval of the study was obtained from the University of Zambia Biomedical Research and Ethics Committee (IRB00001131 of IORG0000774, Reference number 022-06-16). Written consent was obtained from all the participants as well as parental consent for participants under the age of 16 .

\section{Results}

Socio-demographic and cultural characteristics of participants

Table 1 shows the socio-demographic and cultural characteristics of the participants; most of them (48.7\%) were

Table 1 Socio-demographic and cultural characteristics of participants

\begin{tabular}{|c|c|c|c|}
\hline \multicolumn{2}{|l|}{ Demographic Factors } & \multirow{2}{*}{$\begin{array}{l}\text { Frequency } \\
36 \\
208 \\
167 \\
16\end{array}$} & \multirow{2}{*}{$\begin{array}{l}\text { Percent } \\
8.4 \\
48.7 \\
39.1 \\
3.7\end{array}$} \\
\hline Age & $\begin{array}{l}15-24 \\
25-34 \\
35-44 \\
45-49\end{array}$ & & \\
\hline Marital status & $\begin{array}{l}\text { single } \\
\text { married } \\
\text { divorced } \\
\text { widowed }\end{array}$ & $\begin{array}{l}77 \\
320 \\
16 \\
14\end{array}$ & $\begin{array}{l}18 \\
74.9 \\
3.7 \\
3.3\end{array}$ \\
\hline Occupation & $\begin{array}{l}\text { employed } \\
\text { unemployed }\end{array}$ & $\begin{array}{l}108 \\
319\end{array}$ & $\begin{array}{l}25.3 \\
74.7\end{array}$ \\
\hline Education & $\begin{array}{l}\text { primary } \\
\text { secondary } \\
\text { tertiary } \\
\text { none }\end{array}$ & $\begin{array}{l}115 \\
236 \\
73 \\
3\end{array}$ & $\begin{array}{l}26.9 \\
55.3 \\
17.1 \\
0.7\end{array}$ \\
\hline \multicolumn{4}{|l|}{ Cultural Factors } \\
\hline Religion & $\begin{array}{l}\text { Christianity } \\
\text { Other }\end{array}$ & $\begin{array}{l}421 \\
6\end{array}$ & $\begin{array}{l}98.6 \\
1.4\end{array}$ \\
\hline \multirow[t]{2}{*}{ Denomination } & $\begin{array}{l}\text { Pentecostal } \\
\text { Catholic } \\
\text { Adventist }\end{array}$ & $\begin{array}{l}126 \\
82 \\
57\end{array}$ & $\begin{array}{l}29.9 \\
19.4 \\
13.5\end{array}$ \\
\hline & $\begin{array}{l}\text { UCZ } \\
\text { Jehovah's Witness } \\
\text { other }\end{array}$ & $\begin{array}{l}51 \\
28 \\
78\end{array}$ & $\begin{array}{l}12.1 \\
6.6 \\
18.5\end{array}$ \\
\hline Fear of partner discrimination & $\begin{array}{l}\text { Yes } \\
\text { No }\end{array}$ & $\begin{array}{l}152 \\
275\end{array}$ & $\begin{array}{l}35.6 \\
64.4\end{array}$ \\
\hline Fear of family discrimination & $\begin{array}{l}\text { Yes } \\
\text { No }\end{array}$ & $\begin{array}{l}134 \\
293\end{array}$ & $\begin{array}{l}31.4 \\
68.6\end{array}$ \\
\hline \multirow[t]{2}{*}{ Permission to begin ART } & $\begin{array}{l}\text { Yes } \\
\text { No }\end{array}$ & $\begin{array}{l}134 \\
293\end{array}$ & $\begin{array}{l}31.4 \\
68.6\end{array}$ \\
\hline & Total & 427 & 100 \\
\hline
\end{tabular}


within the age of 25-34 years with a mean age of 30 . Majority $(74.9 \%)$ were married at the time of the study and were not in formal employment. The educational levels of the respondents showed that $55.3 \%$ had reached secondary school while very few (17.1\%) attained tertiary education. Regarding the socio-cultural factors, this study showed that most of the participants were Christian (98.6\%) belonging to different Christian denominations. Thirty five percent (35\%) of the participants expressed that their partners would discriminate them if they found out that they were on ART and most of them (68.6\%) said they would not need permission from their partners or family members before initiating ART.

\section{Acceptability, level of knowledge and attitudes towards option B+}

Table 2 shows that out of the 427 participants, only $45.9 \%$ had adequate knowledge of Option B+. Despite the level of knowledge found, most of them (63.2\%) had good attitude towards Option $\mathrm{B}+$ and overall, majority (77.8\%) were willing to be on ART for life.

\section{Predictors of acceptability using logistic regression analysis}

Table 3 shows the results of the logistic regression analysis. The univariate model showed that women who feared partner or family discrimination were less likely to accept Option $\mathrm{B}+$ than those that believed that they would not be discriminated. Those with adequate knowledge were 2 times more likely to accept Option $\mathrm{B}+$ than those with inadequate knowledge [OR: 2.1 (95\%CI, 1.3-3.3)]. Attitude of women was observed to be statistically associated with acceptability with those with good attitude being 9 times more likely to accept Option B+ than those with a bad attitude [OR: 9.4 (95\%CI, 5.8-15.2)].

All factors that were found to be significant in the univariate model were put in the multivariate model. The results show that attitude was the only factor significantly

Table 2 Level of knowledge and attitudes towards Option B+ among participants

\begin{tabular}{lll}
\hline & Frequency & Percent \\
\hline Knowledge level & & \\
Adequate Knowledge & 196 & 45.9 \\
$\quad$ Inadequate knowledge & 231 & 54.1 \\
$\begin{array}{l}\text { Specific attitudes towards Option B+ } \\
\text { Good attitude }\end{array}$ & 270 & \\
Bad attitude & 157 & 63.2 \\
Overall Acceptability & & 36.8 \\
yes & 332 & \\
no & 95 & 77.8 \\
Total & 427 & 22.2 \\
\hline
\end{tabular}

associated with acceptability of Option B+ [AOR: 9.2 (95\%CI, 5.7-15.1)]. Participants with good attitude were 9 times more likely to accept Option B+ than those that had a bad attitude.

\section{Discussion}

The majority of HIV positive women receiving antenatal and postnatal care services in this study accepted lifelong treatment. Similarly, studies from Malawi and Zimbabwe on the acceptability of Option $\mathrm{B}+$ among pregnant and breastfeeding women showed that women accepted ART for life $[4,11]$.

While the women in this study generally accepted Option $\mathrm{B}+$, there is still a gap in the knowledge levels. The study showed that over half $(54.1 \%)$ of the participants had inadequate knowledge of Option $\mathrm{B}+$. These findings were consistent with a study conducted in Tanzania which showed inadequate knowledge on treatment and prevention for HIV infected pregnant women: only $34 \%$ knew that HIV-infected pregnant woman could be on ART and $47 \%$ did not know that antiretroviral (ARVs) should be used throughout life [7]. A similar study from Ethiopia shows contradicting results, which was; most of the participants (58\%) had adequate knowledge of PMTCT Option B+ [6]. The results of this study highlight a clear need for proving more information on Option $\mathrm{B}+$ to the general population, women who attend antenatal and postnatal visits at health facilities as well as the benefits of being initiated on Option B+ early.

Regarding the socio-cultural factors, no association was observed between religion and denomination with willingness to accept option $\mathrm{B}+$. The differences in the denominations among the women in this study did not affect acceptability. This is in line with a study that was conducted in Tanzania which showed that belief in the healing power of prayer was not significantly associated with a person's hypothetical willingness to begin ARV treatment if they became HIV infected [12]. On the contrary, a study conducted in Ghana indicates that some respondents still held the opinion that HIV is a spiritual disease and therefore there is the need to seek spiritual interventions. Some defaulters cited "use of alternative medicines" as a reason for not going for antiretrovirals and others sleep in prayer camps. This causes them to default most often. However as disease progression among these groups becomes rapid they return to the health facility to continue treatment with ARVs [8].

This study also revealed that about $30 \%$ of the women still experience HIV related stigma and discrimination from their partners and families which may affect the acceptability of life-long treatment. Those who stated that their partner and family would discriminate them were less likely to accept Option B+ compared to those that believed they would not be discriminated. Research has 
Table 3 Logistic regression analysis on acceptability of Option B+ in relation to potential predictors

\begin{tabular}{|c|c|c|c|c|}
\hline Predictor variable & COR (95\% Cl) P-Value & & AOR $(95 \%$ Cl) P-Value & \\
\hline \multicolumn{5}{|l|}{ Employment status } \\
\hline Employed & 1 & & - & - \\
\hline Unemployed & $0.8(0.5-1.4)$ & 0.427 & & \\
\hline \multicolumn{5}{|l|}{ Marital status } \\
\hline Single & 1 & & & \\
\hline Married & $1.9(1.1-3.2)$ & 0.028 & & \\
\hline Divorced & $2.1(0.5-8.0)$ & 0.284 & & \\
\hline Widowed & $6.25(0.8-50.5)$ & 0.086 & $1.0(0.6-1.7)$ & 0.903 \\
\hline \multicolumn{5}{|l|}{ Education level } \\
\hline None & 1 & & & \\
\hline Primary & $1.4(0.1-16.2)$ & 0.779 & & \\
\hline Secondary & $1.86(0.17-20.9)$ & 0.615 & - & - \\
\hline Tertiary & $2.1(0.18-24.9)$ & 0.554 & & \\
\hline \multicolumn{5}{|l|}{ Age } \\
\hline$>=35$ & 1 & & & \\
\hline $15-34$ & $0.6(0.3-1.1)$ & 0.099 & - & - \\
\hline \multicolumn{5}{|l|}{ Religion } \\
\hline Other & 1 & & - & - \\
\hline Christianity & $3.6(0.7-18.0)$ & 0.122 & & \\
\hline \multicolumn{5}{|c|}{ Christian Denomination } \\
\hline Catholics & 1 & & - & - \\
\hline Protestants & $1.1(0.6-2.0)$ & 0.794 & & \\
\hline \multicolumn{5}{|c|}{ Fear of partner discrimination } \\
\hline No & 1 & & & \\
\hline Yes & $0.7(0.2-1.2)$ & 0.003 & $1.0(0.5-2.0)$ & 0.901 \\
\hline \multicolumn{5}{|c|}{ Fear of family discrimination } \\
\hline No & 1 & & & \\
\hline Yes & $0.5(0.02-1.0)$ & 0.041 & $0.7(0.4-1.4)$ & 0.308 \\
\hline \multicolumn{5}{|c|}{ Permission to begin ART } \\
\hline No & 1 & & - & - \\
\hline Yes & $1.2(0.7-2.0)$ & 0.481 & & \\
\hline \multicolumn{5}{|l|}{ Knowledge } \\
\hline Inadequate & 1 & & & \\
\hline Adequate & $2.1(1.3-3.3)$ & 0.003 & $1.3(0.7-2.4)$ & 0.356 \\
\hline \multicolumn{5}{|l|}{ Attitude } \\
\hline Bad & 1 & & & \\
\hline Good & $9.4(5.8-15.2)$ & 0.0001 & $9.3(5.7-15.2)$ & 0.0001 \\
\hline
\end{tabular}

shown that stigma and discrimination undermine HIV prevention efforts by making people afraid to seek HIV information, services and modalities to reduce their risk of infection and to adopt safer behaviour's lest these actions raise suspicion about their HIV status [13].

With regards to getting permission from partner or family, most women in this study said they would not need any permission from their partners or family members before initiating ART for life. This implies that most women would not reject ART for life due to failure to get consent from partner/family. A study conducted in Malawi on Acceptability of lifelong treatment (Option $\mathrm{B}+$ ) found contradicting results. The women were overwhelmed with the information, needed time to 
think about ART initiation and wanted to first discuss with their partners before committing to lifelong treatment [4].

Women in this study generally had a good attitude towards Option $\mathrm{B}+$. Though receiving ART for life can be a burden; most of the women felt that they would not have problems with initiating ART for life. The good attitude found among the women could be attributed to the hope that ART can help improve the quality of life, survival and also benefit their children. This hope has helped change the negative attitudes towards lifelong treatment. Furthermore, the women with good attitude were more likely to accept Option B+ than the women with a bad attitude. This simply shows that the more the women develop a good attitude towards Option $\mathrm{B}+$, the more the willingness to accept it. These findings were consistent with other research findings that have also shown that majority of the study participants 199 (66.1\%) had positive attitude about PMTCT option B+ service [10]. A similar study conducted in Ethiopia reviewed that $76.3 \%$ of participants had positive attitude while others had poor attitude [6]. In order to have more HIV positive women on Option $\mathrm{B}+$, intensive counselling needs to be done to help change the negative behaviours of some women.

However, this study has potential limitations that should be noted. Firstly this study was based on a cross-sectional design which does not show causal relationships. Secondly, Women who had been receiving ART prior to 2013 when Option B+ was implemented were included in this study. Generalization of the study findings was limited to selected health facilities of Lusaka District hence future studies should involve health facilities across the country.

\section{Conclusion}

This study reveals that majority of the participants in this setting accepted the lifelong treatment of Option B + . Their attitudes towards it were generally good. However, we have found inadequacy on the level of knowledge of Option $\mathrm{B}+$ which suggests need for efforts to help individuals and the broader communities have a better understanding of Option $\mathrm{B}+$ as a preventive measure for HIV among women and their unborn children. Redesigning health educational strategies on PMTCT and ART for life into local language may reach both the literate and illiterate. There is also need to intensify sensitization programmes in order to successfully combat stigma and discrimination found in this study.

\section{Abbreviations}

ART: Antiretroviral Therapy; ARV: Antiretroviral; EMTCT: Elimination of motherto-child transmission (of HIV); HIV: Human immunodeficiency virus; MTC: Mother to child transmission: PMTCT: Prevention of mother-to-child transmission of HIV; UNAIDS: Joint United Nations Program on HIV/AIDS;
UNICEF: United Nations International Children's Emergency Fund; UTH: University Teaching Hospital; WHO: World Health Organisation

\section{Acknowledgements}

Special thanks go to the health institutions involved in this study, data collectors and all the study participant.

Funding

Not applicable.

\section{Availability of data and material}

The data generated during this study are available without restriction. E-mail chandabridget@gmail.com when needed.

\section{Authors' contributions}

BC designed the study, supervised data collection, analysed the data and drafted the paper. $R L$ and $C J$ contributed in the design of the study. $R L$ and CJ provided scientific advices on data analysis and throughout the preparation of the manuscript. JZ contributed to the designing and drafting of the manuscript. LT contributed to the analysing the data. All authors read and approved the final version of the manuscript.

Ethics approval and consent to participate

Ethical approval of the study was obtained from the University of Zambia Biomedical Research and Ethics Committee (IRB00001131 of IORG0000774, Reference number 022-06-16) prior to conducting the research. Permission to conduct the study in the clinics was first sought from Lusaka District Medical Office. Written consent was obtained from all the participants as well as parental consent for participants under the age of 16. Participants were interviewed separately and no names were attached to responses for confidentiality.

Consent for publication

Not applicable.

\section{Competing interests}

The authors declare that they have no competing interests.

\section{Publisher's Note}

Springer Nature remains neutral with regard to jurisdictional claims in published maps and institutional affiliations.

\section{Author details}

${ }^{1}$ Department of Paediatric and Child Health, University Teaching Hospital-HIV/AIDS Program, P.O Box, 50440 Lusaka, Zambia. ²Department of population studies and Nutrition, School of Public Health, University of Zambia, Geneva, Switzerland. ${ }^{3}$ Department of Epidemiology and Biostatistics, School of Public Health, University of Zambia, Lusaka, Zambia. ${ }^{4}$ Department of Health Promotion and Education, School of Public Health, University of Zambia, Lilongwe, Malawi.

Received: 29 November 2017 Accepted: 11 December 2018 Published online: 29 December 2018

\section{References}

1. UNICEF: Monitoring the situation of women and children, EMTCT. 2017. https://data.unicef.org/topic/hivaids/emtct/. Accessed 17th October, 2017.

2. WHO: Consolidated Guidelines on the use of antiretroviral drugs for treating and preventing HIV infection. Recommendations for a public health approach. Second edition, 2016. http://www.who.int/hiv/pub/arv/arv-2016/ en/. Accessed $2^{\text {nd }}$ May, 2018

3. PEPFAR: Zambia country operational plan, Strateg Dir summary. 2016. https://www.pepfar.gov/documents/organization/222188.pdf. Accessed $20^{\text {th }}$ April, 2018

4. Katirayi L, H. Namadingo, E. Bobrow, A. Yemaneberhan, M. Phiri, S. White, F. Chimbwandira, et al. Acceptability of lifelong treatment (Option B+) among HIV-positive pregnant and lactating women in Selected Sites in Malawi. 2014. EGPAF.

5. Tumbare E, Chadambuka A, Muchedzi A, Mushavi A, Mahomva A. Acceptability of Lifelong antiretroviral treatment (Option B+) among HIV- 
Positive Pregnant and Breastfeeding Women in Selected Sites in Zimbabwe. 2015. Elizabeth Glaser, Paediatric AIDS Foundation.

6. Tsegaye Delelegn. Level of adherence and associated factors to option b+ PMTCT programme among pregnant \& lactating mothers in selected government health facilities of south Wzone, Amhara region, north East Ethiopia. 2016.

7. Agnarson AM, Levira F, Masanja H, Ekström AM, Thorson A Antiretroviral Treatment Knowledge and Stigma-Implications for Programs and HIV Treatment Interventions in Rural Tanzanian Populations. 2013. Tanzania.

8. Boateng D, Kwapong GD and Agyei-Baffour P. Knowledge, perception about antiretroviral therapy (ART) and prevention of mother-to-child transmission (PMTCT) and adherence to ART among HIV positive women in the Ashanti Region, Ghana. 2013.

9. Mhod M. Lived experiences of stigma and discrimination among people on antiretroviral therapy: a qualitative study in ilala municipality, dares salaam. 2013.

10. Kahsay TG. Assessment of Knowledge and Attitude about Prevention of Mother to Child Transmission of HIV Option B+ and associated factors among ANC clients in Dessie town. Addis Ababa, Ethiopia; 2015.

11. Chadambuka A, Muchedzi A, Katirayi L, Tumbare E, Musarandega R, Nyamundaya T, Mutede B, Tachiwenyika E, et al. Acceptability of option B+ among pregnant and breastfeeding women in selected districts in Zimbabwe. 2016.

12. James Z, Yamanaka Y, John M, Watt M, Ostermann J, Thielman N. Religion and HIV in Tanzania: influence of religious beliefs on HIV stigma, disclosure, and treatment attitudes; 2008.

13. UNAIDS: Reduction of HIV-related stigma and discrimination. 2014.

Ready to submit your research? Choose BMC and benefit from:

- fast, convenient online submission

- thorough peer review by experienced researchers in your field

- rapid publication on acceptance

- support for research data, including large and complex data types

- gold Open Access which fosters wider collaboration and increased citations

- maximum visibility for your research: over $100 \mathrm{M}$ website views per year

At $\mathrm{BMC}$, research is always in progress.

Learn more biomedcentral.com/submissions 